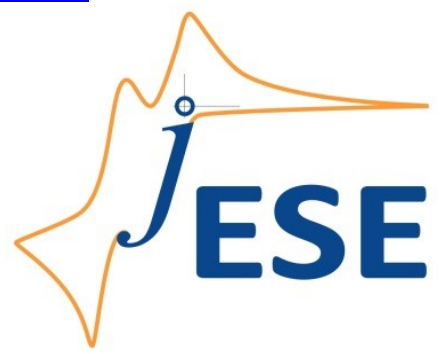

Open Access : : ISSN 1847-9286

www.jESE-online.org

Original scientific paper

\title{
Electrochemical behaviour of selenite ions in tartaric electrolytes
}

Vusala Asim Majidzade ${ }^{1, 凶}$, Akif Shikhan Aliyev ${ }^{1}$, Parvin Haydar Guliyev², Yasin Nagi Babayev², Mahmoud Elrouby ${ }^{3}$, Dilgam Babir Tagiyev ${ }^{1}$

${ }^{1}$ NAS of Azerbaijan, Institute of Catalysis and Inorganic Chemistry named after M. Nagiyev, Baku, Azerbaijan

${ }^{2}$ Nakhchivan State University, Nakhchivan, Azerbaijan

${ }^{3}$ Chemistry Department, Faculty of Science, Sohag University, Sohag, Egypt

Corresponding authors - E-mail: ${ }^{凶}$ vuska 80@mail.ru, Phone: +99450 6400225

Received: December 12, 2017; Revised: January 22, 2018; Accepted: January 24, 2018

\begin{abstract}
In recent years, a great interest has been emerged on electrochemical preparation of semiconductor films based on selenium. Therefore, a study of electrochemical reduction of selenium could be very important. In this work, the kinetics and mechanism of the electrochemical reduction of selenite ions on the Pt cathode have been studied in the electrolyte containing selenious and tartaric acids. The study shows that electroreduction of selenite ions from tartaric electrolytes proceeds in two stages. The effect of various factors on the cathodic reduction of selenium ions has also been studied. The effective activation energy was calculated using the polarization curves of the temperature dependence of the electroreduction process of selenite ions. It was established that the process of electroreduction under investigation is proceeding by mixed kinetics, at first by concentration and then by electrochemical polarization.
\end{abstract}

\section{Keywords}

Selenite ions; Tartaric acid; Electrochemical reduction; Polarization; Cyclic voltammetry

\section{Introduction}

Progress of the modern science and technology is closely related to formation of traditional semiconductor materials, as well as formation and exploration of new promising semiconductors what become one of the urgent problem facing scientists. Different physical properties of semiconductor materials create wide opportunities for their application in modern electronics and electrical engineering [1-3]. They are used in modern computers, light diodes, solar cells, lasers, and photodetectors. As is already known, selenium element is one of the important semiconductors with wide scope of applications. For example, selenium is important technological and biological 
element used in industry and medicine. In non-ferrous metallurgy, processing of raw material containing selenium as pulp and paper products is one of the selenium related industrial area. Selenium is available in the form of various chemical compounds in many natural materials such as organic fertilizers, water, living organisms and plants. The biological properties of selenium are ambiguous. At the one side it is vitally important strong adjuvant, antioxidant anti-carcinogenic agent, but at the other side it is very toxic material. The nature of crystal structure and chemical bonds for selenium are rather complex. In spite of the presence of many active defects in the crystal structure, it always has a conductivity of p-type [1]. Effective properties of selenium make it to be a good candidate for photo elements, light diodes, luminescent materials, ionizing radiation detectors, optical filters and sensors, what all open wide opportunities for its usage in industry. Selenium is widely used in production of photo-elements due to the optimal value of the band gap $\left(E_{\mathrm{g}}=1.83 \mathrm{eV}\right)$, direct optical transitions and high absorption coefficient in the visible region of the spectrum [1].

Elemental selenium is also included in the composition of binary and ternary semiconductors, where $\mathrm{Sb}_{2} \mathrm{Se}_{3}$ is one of the most important binary semiconductor compounds. In order to get thin films and coatings of $\mathrm{Sb}_{2} \mathrm{Se}_{3}$ by electrochemical method, the processes of electrodeposition of $\mathrm{Sb}$ and Se should be firstly studied separately. Kinetics and the mechanism of the electroreduction process of antimony on the cathode and the effects of various factors on the deposition process have already been studied [4]. These results, together with the results from a study of the electroreduction of selenite ions on the cathode, would ensure easily obtaining of $\mathrm{Sb}_{2} \mathrm{Se}_{3}$ semiconductor films.

Electroreduction of selenite ions on the cathode has frequently been studied by various researchers [5-10]. On the contrary, the deposition of thin films of selenium by photo electrochemical methods has been rarely studied. The results showed that selenium coatings obtained during illumination have higher quality than selenium coatings obtained in the dark $[5,6]$. The electrochemical behavior of selenide ions has already been studied in different ways on different electrodes such as mercury $(\mathrm{Hg})$, graphite, platinum and other electrodes [7-10]. Synthesis of CulnSe $\mathrm{S}_{2}$ from electrodeposited $\mathrm{Cu}$-In precursors was investigated in [11]. A thermal process was adopted to turn $\mathrm{Cu}$-In precursors into uniform $\mathrm{Cu}_{11} \mathrm{In}_{9}$ binary compounds. The conditions for electrodeposition of $\mathrm{Cu}$, In and Se were adjusted to achieve the preferred atomic proportions. However, the annealing temperature of synthesized $\mathrm{Cu}$-In-Se films from $\mathrm{Cu}_{11} \mathrm{In}_{9}$ was found critical, since the XRD patterns and Raman spectra showed that the $\mathrm{Cu}_{2} \mathrm{Se}$ compound residue is due to an incomplete reaction at lower annealing temperatures. Large dense grains could be grown at $650^{\circ} \mathrm{C}$ for $5 \mathrm{~min}$.

Since the kinetics and mechanism of an electrochemical reduction process should be thoroughly investigated to develop a technology of obtaining a high-quality semiconductor of desired properties based on elemental selenium and its compounds, the present contribution is devoted to a study of the electroreduction process of selenite ions in selenious and tartrate electrolytes on the platinum electrode.

\section{Experimental}

Deposition of selenite ions on the cathode by the electrochemical method was carried out as follows. An electrolyte solution was prepared by dissolving a proper amount of tartaric acid $\left(\mathrm{C}_{4} \mathrm{H}_{6} \mathrm{O}_{6}\right)$ in the distilled water, and then an appropriate amount of selenious acid $\left(\mathrm{H}_{2} \mathrm{SeO}_{3}\right)$ was dissolved in the prepared tartaric acid solution. The composition of the obtained electrolyte consisted of $0.1 \mathrm{~mol} / \mathrm{L} \mathrm{H}_{2} \mathrm{SeO}_{3}+0.007 \mathrm{~mol} / \mathrm{L} \mathrm{C}_{4} \mathrm{H}_{6} \mathrm{O}_{6}$. After that, polarization curves were taken using a 
computerized potentiostat of IVIUMSTAT Electrochemical Interface. All electrochemical experiments were carried out in a three-electrode electrochemical cell. Pt with a surface area of $2 \mathrm{~mm}^{2}$ was used as the working electrode and the Pt sheet of surface area $2 \mathrm{~cm}^{2}$ as the counter electrode, respectively. Silver/silver chloride $(\mathrm{Ag} / \mathrm{AgCl})$ was used as the reference electrode. The temperature of the electrolyte solution during electrolysis was controlled via UTU - 4 universal ultrathermostats.

\section{Results and discussion}

The electroreduction of selenite ions on the Pt cathode has already been studied in alkaline and acidic solutions [12,13], where acidic electrolytes have been found to be more characteristic for electroreduction of selenite ions. In this regard, we have used the tartaric acid as an organic additive electrolyte since this acid has two advantages; firstly, it is an effective solvent and the $\mathrm{H}_{2} \mathrm{SeO}_{3}$ easily dissolved in this solution and secondly, it has a great effect on the brightness and smoothing of electrodeposits.

It is known that selenious acid is a dibasic acid and when dissociated, it forms the $\mathrm{HSeO}_{3}{ }^{-}(1)$ and $\mathrm{SeO}_{3}{ }^{2-}(2)$ anions in solution [14]:

$$
\begin{array}{ll}
\mathrm{H}_{2} \mathrm{SeO}_{3} \leftrightarrow \mathrm{H}^{+}+\mathrm{HSeO}_{3}{ }^{-} & K_{\mathrm{a}}=2.88 \times 10^{-3} \\
\mathrm{HSeO}_{3}{ }^{-} \leftrightarrow \mathrm{H}^{+}+\mathrm{SeO}_{3}{ }^{2-} & K_{\mathrm{a}}=9.55 \times 10^{-9}
\end{array}
$$

As seen from the dissociation constant, $K_{\mathrm{a}}$, values, it is possible to ignore the amount of $\mathrm{SeO}_{3}{ }^{2-}$ ions in relation to $\mathrm{HSeO}_{3}{ }^{-}$ions. Therefore, $\mathrm{H}_{2} \mathrm{SeO}_{3}$ molecules and $\mathrm{HSeO}_{3}{ }^{-}$ions are involved in the process of decomposition of the selenious acid. These processes can be described by the following reactions $[14,15]$ :

$$
\begin{array}{ll}
\mathrm{HSeO}_{3}{ }^{-}+5 \mathrm{H}^{+}+4 \mathrm{e}^{-} \rightarrow \mathrm{Se}+3 \mathrm{H}_{2} \mathrm{O} & E^{0}=0.778 \mathrm{~V} \text { vs. RHE } \\
\mathrm{H}_{2} \mathrm{SeO}_{3}+4 \mathrm{H}^{+}+4 \mathrm{e}^{-} \rightarrow \mathrm{Se}+3 \mathrm{H}_{2} \mathrm{O} & E^{0}=0.740 \mathrm{~V} \text { vs. RHE } \\
\mathrm{HSeO}_{3}{ }^{-}+6 \mathrm{H}^{+}+6 \mathrm{e}^{-} \rightarrow \mathrm{HSe}^{-}+3 \mathrm{H}_{2} \mathrm{O} & E^{0}=0.349 \mathrm{~V} \text { vs. RHE }
\end{array}
$$

Two cathodic peaks ( $A$ and $B$ ) and one anodic peak (C) are noticed in the cyclic voltammetry polarization curves shown in Figure 1.

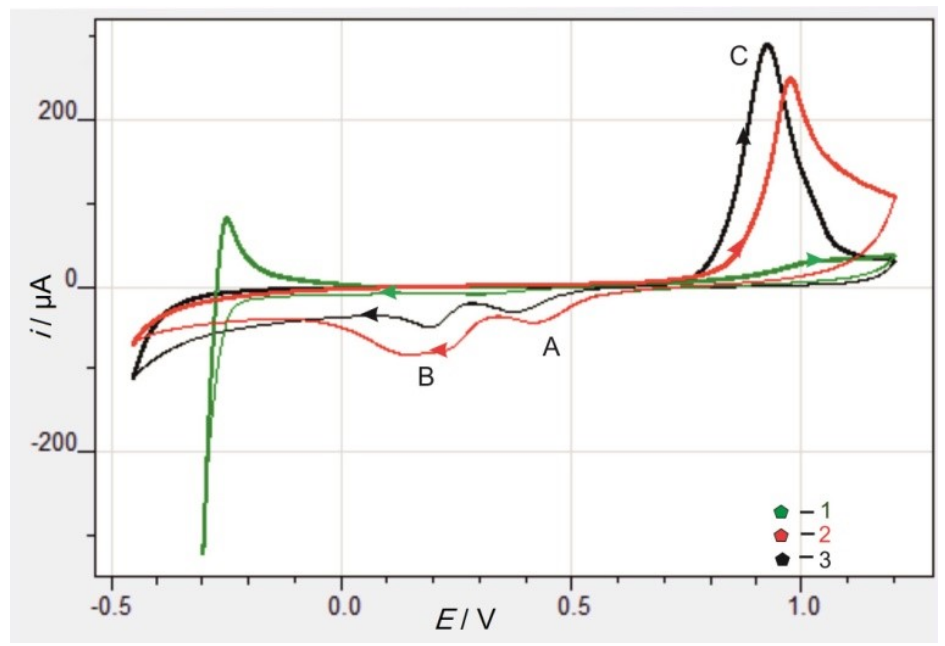

Figure 1. Cyclic voltammetry polarization curves of the Pt electrode. $\mathrm{T}=296 \mathrm{~K}, \mathrm{~V}=0.02 \mathrm{~V} \mathrm{~s}^{-1}$.

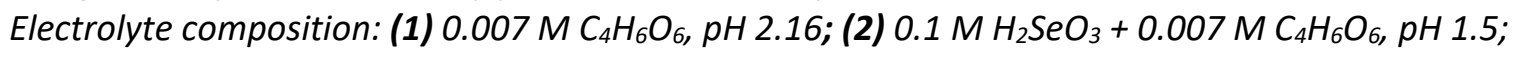

(3) $0.1 \mathrm{M} \mathrm{H}_{2} \mathrm{SeO}_{3}+\mathrm{H}_{2} \mathrm{O}, \mathrm{pH} 1.6$.

Peak $\mathrm{A}$ starts from $0.56 \mathrm{~V}$ to $0.43 \mathrm{~V}$ and attains the peak current value of $-4.4 \times 10^{-5} \mathrm{~A}$, corresponding to the electroreduction of selenite ions by the reaction (3). The surface of an 
electrode is covered with selenium at the value of a peak current and this process continues until the potential value of $0.33 \mathrm{~V}$ was reached. Note that $\mathrm{H}_{2} \mathrm{SeO}_{3}$ molecules and $\mathrm{HSeO}_{3}{ }^{-}$ions are more stable at $\mathrm{pH}$ 1.3-1.5 of the solution. Over time, the concentration of elemental selenium on the surface of the electrode increases and after that, the second cathodic peak B is formed as the result of the reaction (4). Formation of the peak starts at $+0.34 \mathrm{~V}$ and reaches the maximum value at $0.22 \mathrm{~V}$ at which the current value is equal to $-7.8 \times 10^{-5} \mathrm{~A}$. After $0.13 \mathrm{~V}$, the process of conversion of elemental selenium into $\mathrm{HSe}^{-}$ions takes place according to the reaction (5). Peak $\mathrm{C}$ shows the oxidation process of the elemental selenium formed during the electroreduction of selenite ions by reactions 3 and 4 on the Pt electrode.

The impact of a number of factors on the electroreduction process of selenite ions has also been investigated. The electroreduction process at different $\mathrm{pH}$ values were carried out in the range of 2.2-1.5, corresponding to the selenious acid concentration of $0.005-0.1 \mathrm{~mol} / \mathrm{L}$. Based on the measurements polarization curves, the $E_{\mathrm{p}}-f(\mathrm{pH})$ and $\ln i_{\mathrm{p}}-f(\mathrm{pH})$ dependences were constructed and shown in Figure 2.

a



b



Figure 2. $p H$ dependences of: $\boldsymbol{a}$ - peak potential value of peaks $A$ and $B$ and $\boldsymbol{b}$ - logarithmic peak current values of peaks $A$ and peak $B$.

The dependences of the peak potential value on $\mathrm{pH}$ for the peaks $(\mathrm{A})$ and $(\mathrm{B})$ at the concentration interval of $0.005-0.1 \mathrm{~mol} / \mathrm{L}$ of selenious acid are presented in the Figure $2 \mathrm{a}$. As can be seen from the Figure $2 \mathrm{a}$, at $0.1-0.03 \mathrm{~mol} / \mathrm{L}$ concentration range $(\mathrm{pH} 1.5-1.85)$, the potential in the curve $A$ shifts towards the less positive side with the increase in $\mathrm{pH}$, reaches a maximum at $0.025 \mathrm{~mol} / \mathrm{L}(\mathrm{pH} 2.06)$ and then again reduces sharply. For the second peak $B$, the potential is the most positive for $0.1 \mathrm{~mol} / \mathrm{L}(\mathrm{pH} 1.5)$ and gradually moves towards more negative values with increase of $\mathrm{pH}$, reaching a minimum at $0.03 \mathrm{~mol} / \mathrm{L}(\mathrm{pH} 1.85)$. Thus, from the $E_{\mathrm{p}}-\mathrm{pH}$ dependence shown in Fig. $2 \mathrm{a}$, it is obvious that the potential value moves in a positive direction with increase in the concentration of the selenious acid and the corresponding decrease of the $\mathrm{pH}$ value. However, in the Figure $2 \mathrm{~b}$ showing the $\ln i_{\mathrm{p}}$ - $\mathrm{pH}$ curves, the current values of current increase with decrease of the $\mathrm{pH}$ value or increase of the concentration of the selenious acid. This means that the current spent on the electroreduction process reaches a maximum value at $\mathrm{pH}>2$. Selenite ion concentration also affects the quality of gold-and-red-colored selenium films deposited on the surface of the electrode. 
Figure 3 shows the effect of concentration in the selenious acid in the range of $0.005-0.1 \mathrm{M}$ on the rate of the electroreduction process. It is observed that the rate of the electroreduction process increases by increasing the concentration of selenite ions.



Figure 3. Effect of the concentration of selenite ion on reduction process on Pt electrode: (1) 0.005;

(2) 0.025 ; (3) 0.03; (4) 0.05; (5) 0.08; (6) $0.1 \mathrm{M}$. Electrolyte composition: $0.007 \mathrm{M} \mathrm{C}_{4} \mathrm{H}_{6} \mathrm{O}_{6}$,

$$
T=296 K, v=0.02 \mathrm{Vs}^{-1} \text {. }
$$



Figure 4. Effect of scan rate on electroreduction of selenite ions on Pt electrode: (1) 0.005 ; (2) 0.01 ; (3) 0.03 ; (4) 0.05 ; (5) 0.08 ; (6) 0.12 ; (7) $0.2 \mathrm{~V} \mathrm{~s}^{-1}$. Electrolyte composition:

$0.1 \mathrm{M} \mathrm{H}_{2} \mathrm{SeO}_{3}+0.007 \mathrm{M} \mathrm{C}_{4} \mathrm{H}_{6} \mathrm{O}_{6}, \mathrm{~T}=296 \mathrm{~K}, \mathrm{pH} 1.5$

One of the factors affecting the reduction process of selenite ions is the scan rate of potential changes. The effect of the scan rate on the reduction process of selenite ions was studied in the range of 0.005-0.2 $\mathrm{V} \mathrm{s}^{-1}$ and the cyclic polarization curves are shown in Figure 4.

From polarization curves given in Figure 4, it appears that the scan rate has a significant impact on the reduction process. The current height of peaks formed during the electroreduction process is directly proportional to the value of the scan rate. Thus, the peak current value at the scan rate of $0.005 \mathrm{~V} \mathrm{~s}^{-1}$ is equal to $-1.52 \times 10^{-5} \mathrm{~A}$ for the first peak $\mathrm{A}$ and $-1.32 \times 10^{-5} \mathrm{~A}$ for the second peak $\mathrm{B}$, respectively. At the scan rate of $0.2 \mathrm{~V} \mathrm{~s}^{-1}$, however, the peak current values are higher and equal to $-5.04 \times 10^{-4} \mathrm{~A}$ for the first peak $\mathrm{A}$ and $-1.0 \times 10^{-3} \mathrm{~A}$ for the second peak $\mathrm{B}$, respectively.

The effect of temperature on the rate of electroreduction process on the Pt cathode has been also studied in the 296-348 $\mathrm{K}$ range and the results are shown in Figure 5.



Figure 5. Effect of temperature on electroreduction of selenite ion on Pt electrode:

(1) 296; (2) 308; (3) 318; (4) 328; (5) 338; (6) $348 \mathrm{~K}$.

Electrolyte composition: $0.1 \mathrm{M} \mathrm{H}_{2} \mathrm{SeO}_{3}+0.007 \mathrm{M} \mathrm{C}_{4} \mathrm{H}_{6} \mathrm{O}_{6}, \mathrm{v}=0.02 \mathrm{~V} \mathrm{~s}^{-1}, \mathrm{pH} 1.5$. 
From the cyclic polarization curves shown in Figure 5, it appears that by increasing the temperature, the reduction potential of selenite ions gradually moves in the positive direction. At the same time, the peak of the anodic current shifts in the negative direction with increase of temperature up to $348 \mathrm{~K}$ with the simultaneous increase of current values. These suggest that acceleration of the anodic process takes place with an increase of the temperature. Based on the polarization curves of the temperature effect shown in Figure 5, the $\log i_{k}-1 / T$ dependences were derived and presented in Figure 6. Based on tg $\alpha$ values obtained from the slopes of linear graphs, the effective activation energy, $A_{\text {ef, }}$ were calculated. The calculated $A_{\text {ef }}-E$ dependence is shown in Figure 7.
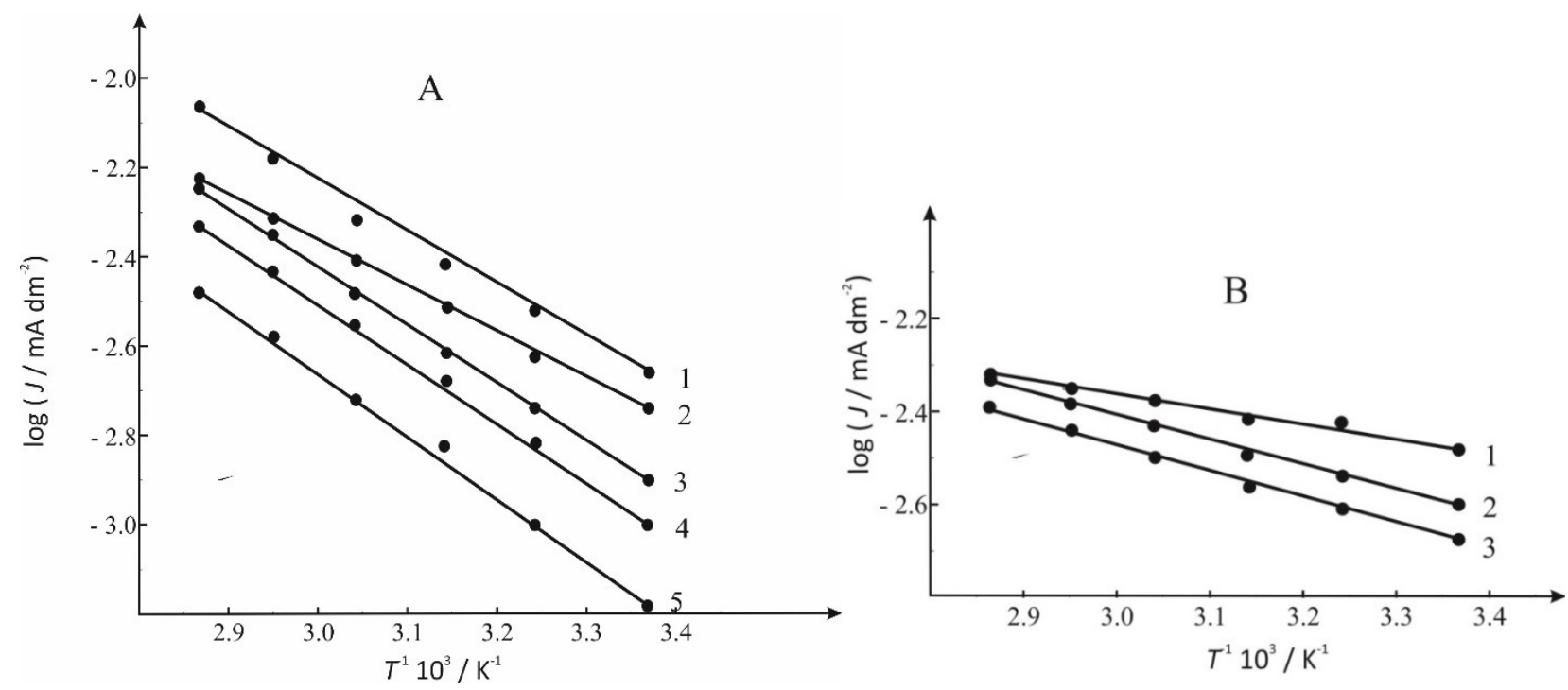

Figure 6. $\log \mathrm{i}_{k}-1 / \mathrm{T}$ dependence constructed from Fig. 5 at different selected cathodic potentials
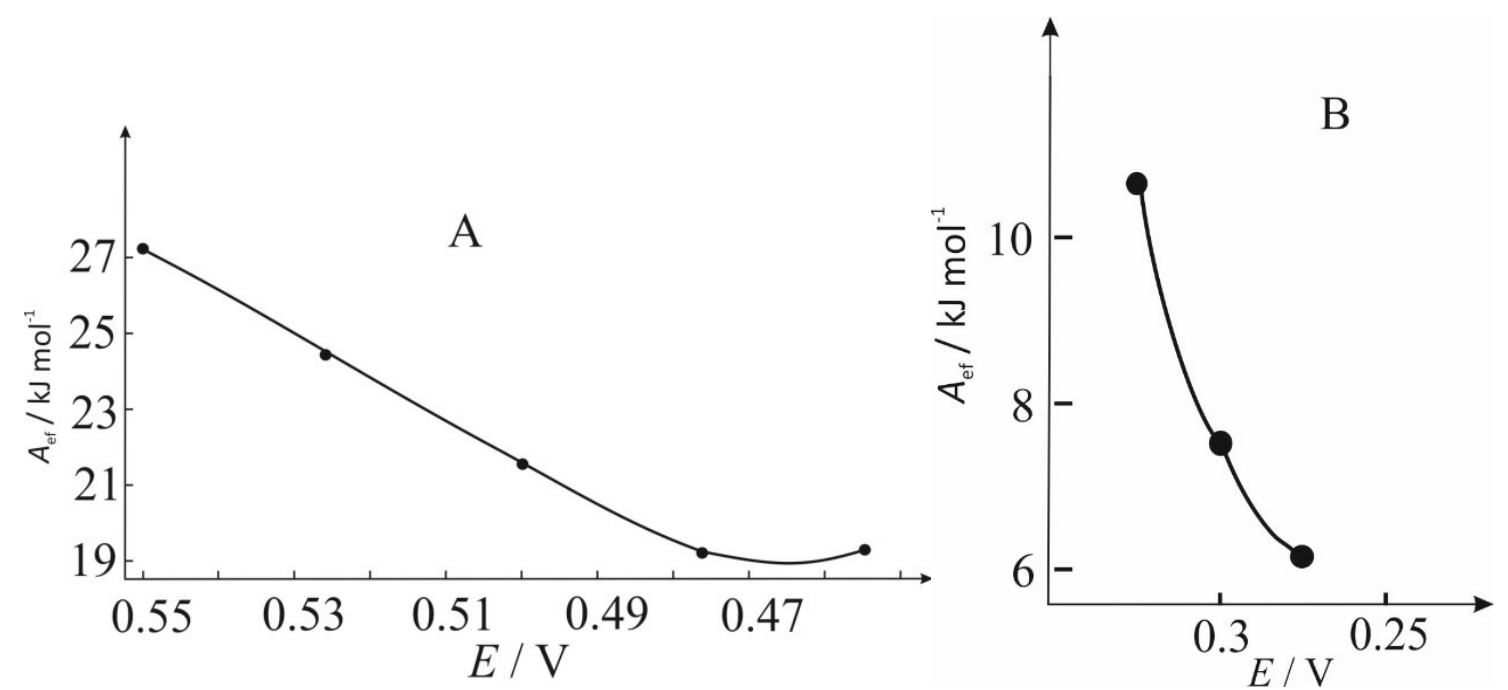

Figure 7. Dependence of the calculated activation energy on the selected cathodic potentials

The obtained results show that, the polarization in the reduction process of selenite ions according to the first peak is of concentration nature, and the one of the second peak is of electrochemical nature. This may be explained by the fact that, the first reduction process proceeding by eq. (3) takes place depending on the transport rate of the selenite ions to the electrode surface, and the reduction of the $\mathrm{H}_{2} \mathrm{SeO}_{3}$ proceeding by eq. (4) is based on the electrochemical reaction. The effect of temperature has also a significant impact on the adhesion of selenium film deposited on the surface of the electrode as a result on the uploading selenite ions on the cathode. As the temperature rises the collapse of deposited films from surface is observed. 
By performing several experiments in this regard, it has been found that the surface films having good adhesion are obtained within the temperature range of $296-318 \mathrm{~K}$.

The impact of the electrode material on the electroreduction process of selenite ions has been investigated by comparing the results obtained using $\mathrm{Pt}$ and $\mathrm{Pt} / \mathrm{Se}$ surfaces and presented in Figure 8.

From the cyclic polarization curves shown in Figure 8, it appears that the cathodic currents are higher for the reduction process on the Pt than the $\mathrm{Pt} / \mathrm{Se}$ electrode. This is due to the fact that selenium is a semiconductor. One can assume that the entry of Se ions into the cage of Pt/Se takes place easier than on Pt. From the anodic branch of the polarization curve shown in Figure 8, it is seen that the oxidation of selenium on the Pt electrode occurs at lower current values than on the $\mathrm{Pt} / \mathrm{Se}$ electrode. This is due to the fact that before the reduction of the selenite ions on the Pt/Se electrode there is already a selenium layer present on the electrode surface and dissolution occurs at higher current values than for the Pt electrode.

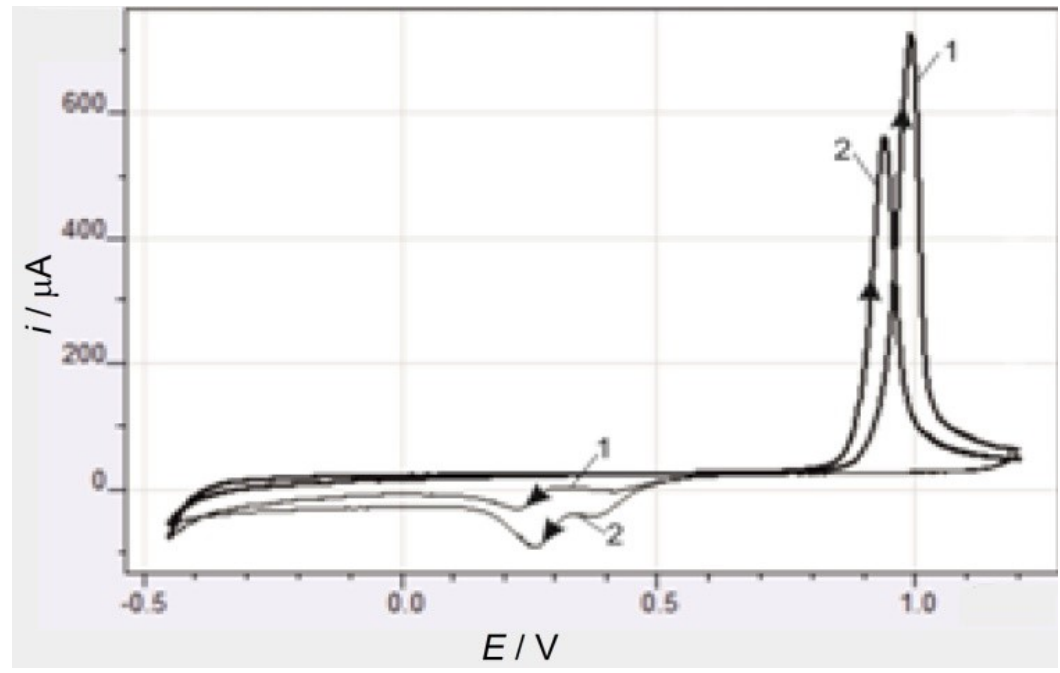

Figure 8. Effect of the electrode material on electroreduction of selenite ions on: 1) Pt/Se and 2) Pt electrodes. Electrolyte composition: $0.1 \mathrm{M} \mathrm{H}_{2} \mathrm{SeO}_{3}+0.007 \mathrm{M} \mathrm{C}_{4} \mathrm{H}_{6} \mathrm{O}_{6}, \mathrm{~V}=0.02 \mathrm{~V} \mathrm{~s}^{-1}, T=296 \mathrm{~K}, \mathrm{pH} 1.5$.

\section{Conclusions}

The cathodic reduction process of selenite ions from selenious and tartaric acid electrolyte on the Pt electrode has been studied using the cyclic polarization curves. Influence of temperature, concentration, $\mathrm{pH}$, scan rate of potential and other factors to the reduction process have been studied. The results showed that the electroreduction of $\mathrm{H}_{2} \mathrm{SeO}_{3}$ and $\mathrm{HSeO}_{3}{ }^{-}$forming $\mathrm{Se}$ and $\mathrm{HSe}^{-}$occurs at a potential of 0.56 to $-0.45 \mathrm{~V}$. The kinetics and mechanism of electrochemical reduction of selenite ions on the Pt cathode have been studied. It was found that the reduction process is proceeding by mixed kinetics, firstly by concentration, and then by electrochemical polarization. The experimental results showed that the optimal reduction process occurs at $0.1 \mathrm{~mol} / \mathrm{L} \mathrm{H}_{2} \mathrm{SeO}_{3}+0.007 \mathrm{~mol} / \mathrm{L} \mathrm{C}_{4} \mathrm{H}_{6} \mathrm{O}_{6}$ - containing electrolyte, $T=296 \mathrm{~K}, v=0.02 \mathrm{~V} \mathrm{~s}^{-1}$ and at pH 1.5 .

\section{References}

[1] I. A. Sluchinskaya Fundamentals of materials science and semiconductor technology, Mir, Moscow, in Russia, 2002, p. 376 (in Russian).

[2] A. A. Kovalev, S. P.Zhvaviy, G. L. Zykov, Physics and Engineering of Semiconductors 39(11) (2005) 1345-1349.

[3] A. Sh. Aliyev, Sh. O. Eminov, T. Sh. Soltanova, V. A. Mejidzadeh, D. A. Kuliyev, H. D. Jalilova, D. B. Tagiyev, Chemical Problems 2 (2016) 139-145 (in Azerbaijan). 
[4] V. A. Majidzade, P. H. Guliyev, A. Sh. Aliyev, M. Elrouby, D.B. Tagiyev, Journal of Molecular Structure 1136 (2017) 7-13.

[5] M. B. Dergacheva, K. A. Maeva, N. N. Gudeleva, K. A. Urazov, V. P. Grigoryev News of the National Academy of Sciences; A Series of Chemistry and Technology 5 (2012) 54-61.

[6] M. B. Dergacheva, N. V. Penkova, K. A. Urazov, K. A. Maeva, Bulletin of Kazakh National University named after Al-Farabi Chemistry Series 3(63) (2011) 101-104.

[7] M. B. Dergacheva, N. V. Penkova, K. A. Urazov, K. A. Maeva, Actual Achievements of European Science, VII International Scientific and Practical Conference, Bulgaria, 2011, p. 6.

[8] M. B. Dergacheva, K. A. Leontiev, N. N. Gudeleva, G. M. Husurova, K. A. Urazov, Proceedings of the National Academy of Sciences of the Republic of Kazakhstan Chemistry and Technology Series 1(409) (2015) 76-84.

[9] Y. N. Zhiharev, D. I. Elantsev, M. A.Kuznetsov, Herald of Tyumen State University 2 (2003) $226-230$.

[10] A. B. Baeshov, G. S. Serazitdinova, S. A. Baeshova, Proceedings of the National Academy of Sciences of the Republic of Kazakhstan, Series Chemistry 1 (2006) 24-26.

[11] T.-W. Chang, S.-Y. Hu, W.-H. Lee, Journal of Electrochemical Science and Engineering 4 (1) (2014) 2735

[12] A. Sh. Aliyev, M. N. Mamedov, Z. F. Gyulahmedova, Azerbaijan Journal of Chemistry 1 (2007) 72-77.

[13] V. A. Majidzade, European Conference on Innovations in Technical and Natural Sciences, $10^{\text {th }}$ International scientific conference, Vienna, Austria, 2016, p.164.

[14] D. Dobos, Electrochemical Data, Verlag Akadémiai Kiadó, Budapest, 1975, p. 353.

[15] Handbook of Electrochemistry, A. A. Sukhotin, Ed., Chemistry, Leningrad, 1981, p. 488 (in Russian).

(C)2018 by the authors; licensee IAPC, Zagreb, Croatia. This article is an open-access article distributed under the terms and conditions of the Creative Commons Attribution license

(http://creativecommons.org/licenses/by/4.0/) 